\title{
马尾松人工林伐桩储量与分解特征
}

\author{
汪 $\quad$ 沁 $^{1}$ 杨万勤 $1,2^{*}$ 吴福忠 ${ }^{1,2}$ 张 健 ${ }^{1,2}$ 谭 波 ${ }^{1,2}$ 张禾涛 $^{1}$
}

${ }^{1}$ 四川农业大学生态林业研究所, 长江上游林业生态工程省级重点实验室, 成都 $611130{ }^{2}{ }^{2}$ 长江上游生态安全协同创新中心, 成都 611130

摘 要 伐桩在人工林生态系统地力维持、碳吸存、生物多样性保育、水土保持等方面具有十分重要的意义, 但对其储量及 其分解特征的研究并不多见。因此, 该文作者基于马尾松(Pinus massoniana)人工林采伐档案, 2013年7月以1999-2013年间采 伐残留的伐桩为研究对象, 调查了 1-15年伐桩系统的木桩(SW)、树皮(B)、根桩(SR), 以及不同径级根系(R1: $0 \mathrm{~mm}<$ 径级 $\leqslant 10$ $\mathrm{mm}$; R2: $10 \mathrm{~mm}$ <径级 $\leqslant 25 \mathrm{~mm}$; R3: $25 \mathrm{~mm}$ <径级 $\leqslant 100 \mathrm{~mm}$; R4: 径级> $100 \mathrm{~mm}$ )的储量与分解特征。研究结果表明: 马尾松 人工林整个伐桩系统储量介于 $5-58 \mathrm{t} \cdot \mathrm{hm}^{-2}$ 之间, 根桩储量最大, 木桩储量次之, 树皮储量最小, 根桩、木桩和树皮的储量均随 着分解时间而降低。伐桩密度随分解时间而降低，但木桩、根桩和粗根径级均显著影响密度的变化。木桩、树皮和根桩的分 解常数分别为 $0.061 、 0.027 、 0.036, \mathrm{R} 1 、 \mathrm{R} 2 、 \mathrm{R} 3 、 \mathrm{R} 4$ 根系的分解常数分别为 $0.079 、 0.042 、 0.047 、 0.119$ 。由此可见, 马尾松 人工林伐桩系统具有较高的储量，但分解较慢，且不同组分的降解速率具有显著差异。

关键词 马尾松人工林; 伐桩; 分解序列; 储量; 分解特征

引用格式: 汪沈, 杨万勤, 吴福忠, 张健, 谭波, 张䇛涛 (2016). 马尾松人工林伐桩储量与分解特征. 植物生态学报, 40, 458-468. doi: $10.17521 /$ cjpe.2015.0313

\section{Characteristics of stump stock and decomposition in Pinus massoniana plantation}

\author{
WANG Qin ${ }^{1}$, YANG Wan-Qin ${ }^{1,2 *}$, WU Fu-Zhong ${ }^{1,2}$, ZHANG Jian ${ }^{1,2}$, TAN Bo ${ }^{1,2}$, and ZHANG Xi-Tao ${ }^{1}$ \\ ${ }^{1}$ Sichuan Agricultural University Institute of Forestry \& Ecology, Sichuan Provincial Key Laboratory of Forestry Ecological Engineering in the Upper Reaches of Yangtze \\ River, Chengdu 611130, China; and ${ }^{2}$ Collaborative Innovation Center of Ecological Security in the Upper Reaches of Yangtze River, Chengdu 611130
}

\begin{abstract}
Aims Stump plays crucial roles in maintaining soil fertility, sequestering carbon, nursing biodiversity, and conserving soil and water in plantation ecosystems. However, little is known about the decay of stump and the related roots in Pinus massoniana plantations. This study aims to explore the characteristics of stump stock and decomposition in the $P$. massoniana plantation.

Methods Based on log file records of P. massoniana plantation from Laifu Forestry Management Institute in Yibin City of Sichuan Province, we established a chronosequence of decaying P. massoniana stumps from 1999 to 2013. We then investigated the stock and density of stump wood (SW), bark (B), stomp root (SR), and linked roots with different diameters (R1: $0 \mathrm{~mm}<$ diameter $\leqslant 10 \mathrm{~mm}$; R2: $10 \mathrm{~mm}<$ diameter $\leqslant 25 \mathrm{~mm}$; R3: $25 \mathrm{~mm}<$ diameter $\leqslant 100 \mathrm{~mm}$; R4: diameter $>100 \mathrm{~mm}$ ).

Important findings In the investigated P. massoniana plantations, the stump stocks ranged from 5 to $58 \mathrm{t} \cdot \mathrm{hm}^{-2}$, stocks in stump wood was the largest, in stump root as the second, and in bark was the smallest, which decreased with the decomposing time. Correspondingly, stump density decreased with decomposing time, while the changes in density varied with stump wood, stump root and roots with different diameters. The decomposition constants of stump wood, bark and stump root were estimated at $0.061,0.027$ and 0.036 , respectively. The decomposition constants of roots were estimated to be 0.079 for R1, 0.042 for R2, 0.047 for R3 and 0.119 for R4, respectively. In conclusion, the $P$. massoniana plantation has a high stock, but decomposes slowly and the decomposition constant varies greatly with stump components in the P. massoniana plantation, which provides certain theoretical basis for the sustainable management of $P$. massoniana plantation in the region.
\end{abstract}

Key words Pinus massoniana plantation; stump; decomposition sequence; stock; decomposition characteristics

Citation: Wang Q, Yang WQ, Wu FZ, Zhang J, Tan B, Zhang XT (2016). Characteristics of stump stock and decomposition in Pinus massoniana plantation. Chinese Journal of Plant Ecology, 40, 458-468. doi: 10.17521/cjpe.2015.0313

收稿日期Received: 2015-09-06 接受日期Accepted: 2016-01-17

* 通信作者Author for correspondence (E-mail: scyangwq@163.com) 
粗木质残体(CWD)是森林生态系统中重要的结 构性和功能性组成要素(Harmon et al., 1986), 在地 力维持、生物多样性保育、水源涵养和森林更新等 方面具有十分重要的作用(侯平和潘存德, 2001)。作 为人工林的采伐剩余物, 伐桩(stump)是人工林生态 系统最重要的粗木质残体, 其在人工林地力维持、 水土保持和碳吸存等方面具有重要的生态功能 (Persson, 2013)。为了理解伐桩的生态系统功能, 国 内外学者针对人工林伐桩的碳与养分动态 (Stromgren et al., 2013)、大型真菌保育(Cleary et al., 2013)、无脊椎动物保育(Ols et al., 2013)、幼苗更新 (Saksa, 2013)等进行了大量的科学研究。然而, 伐桩 分解时间长(黄志群等, 2005), 受研究手段限制, 有 关人工林伐桩分解过程的研究相对较少(Persson et al., 2013), 而且对人工林伐桩碳储量的估计误差为 2\%-10\%。此外，伐桩由木桩(树皮、木材)、根桩以 及不同径级的根系组成, 而且所处的分解环境差异 较大, 从而导致了不同的分解过程。但迄今为止, 尚 未见相关的研究报道。事实上, 在人工林生态系统 的经营与管理中, 不同采伐时间留下的伐桩剩余物 为理解人工林伐桩储量及分解特征提供了重要的研 究材料。因此, 根据人工林采伐记录档案, 采用倒推 法建立伐桩分解序列实验, 可以较为清晰地了解人 工林生态系统伐桩储量与分解特征。

马尾松(Pinus massoniana) 具有耐干旱㾉薄、适 应能力强等特点, 是我国南方低山丘陵区的主要造 林树种, 在经济建设和生态建设中具有重要的作用 (康冰等, 2009; 张克荣等, 2011)。为了可持续经营与 管理马尾松人工林生态系统, 我国科研人员针对马 尾松人工林生态系统的养分循环等进行了研究(项 文化和田大伦, 2002; 莫江明等, 2002; 田大伦等, 2004; 杨会侠等, 2010)。然而, 有关马尾松伐桩分解 特征的研究尚未见报道。因此, 本研究以地处长江 上游地区不同采伐时期保留下来的马尾松伐桩为研 究对象, 建立了马尾松伐桩分解序列(1-15年)实验, 研究了马尾松人工林伐桩储量及其分解特征, 以期 为马尾松人工林可持续经营与管理提供科学依据。

\section{1 材料和方法}

\section{1 研究区域概况}

研究区域位于宜宾市高县来复镇森林经营所林

区 $\left(104.53^{\circ}-104.57^{\circ}\right.$ E, 28.57 $-28.60^{\circ} \mathrm{N}$, 海拔 $412-$
$567 \mathrm{~m})$, 地处长江上游和四川盆地南缘, 属中亚热 带湿润季风气候。年平均气温 $18.1{ }^{\circ} \mathrm{C}$, 最高气温 $(7$ 月) $36.8{ }^{\circ} \mathrm{C}$, 最低气温(1月) $7.8{ }^{\circ} \mathrm{C}$, 年降水量 1021 $\mathrm{mm}$ 。土壤为山地黄壤, 土层厚度约 $50 \mathrm{~cm}$ 。原生植 被为亚热带常绿阔叶林, 但现已基本艮殖为马尾松 人工林。林下灌木为梨叶悬钩子(Rubus pirifolius)、 枹栋 (Quercus serrata)、油樟 (Cinnamomum longepaniculatum)、野桐(Mallotus japonicas)、铁仔 (Myrsine africana)、茶荚蒾(Viburnum setigerum)、野 牡丹(Melastoma candidum)等。草本为菜(Pteridium aquilinum)、金星媭(Parathelypteris glanduligera)、 芒(Miscanthus sinensis)、铁芒萁(Dicranopteris linearis)、皱叶狗尾草 (Setaria plicata)、淡竹叶 (Lophatherum gracile)等(谭波等, 2013; Justine et al., 2015)。

\section{2 伐桩分解序列实验}

高县来复森林经营所建于1956年, 是一所以培 育森林、生产与经营木材及木材加工等为主的事业 单位。在长期的人工林经营与管理实践中, 保留了 不同采伐时期的马尾松伐桩。2013年7月, 根据高县 来复镇人工林经营所保存完善的采伐年代记录档 案，以1999-2013年间马尾松人工林采伐保留下来 的伐桩为调查对象，选择采伐林龄为29-30年、坡向 与坡度基本一致、采伐后继续栽植马尾松人工林的 立地(表1), 进行伐桩调查。在每个立地设立 3 个 $20 \mathrm{~m}$ $\times 20 \mathrm{~m}$ 的样地, 对样地内所有伐桩进行调查, 测量 每个伐桩的木桩直径、高度。根据调查结果, 建立 1-15年的伐桩分解序列实验样地。由于2008年采伐 的马尾松人工林的坡向、坡度和其他立地条件与其 他年份的马尾松采伐迹地相比差异太大, 所以在伐 桩分解序列中, 缺乏分解 6 年的伐桩。

在每个样地内选取 5 个与平均直径大小相近的 伐桩, 将其掘出, 在挖掘过程中尽量保证树桩地上 和地下部分的完整性。将伐桩分为木桩(SW)(树桩地 上直径 $\geqslant 10 \mathrm{~cm}$, 长度 $<1 \mathrm{~m}$ 的部分)、树皮(B)、根桩 $(\mathrm{SR})$ (伐桩地下直径 $\geqslant 15 \mathrm{~cm}$, 长度 $<1 \mathrm{~m}$ 的部分)(阎 恩荣等, 2005)和地下粗根 4 个部分, 且粗根按 0-10 mm (R1)、10-25 mm (R2)、25-100 mm (R3)、>100 $\mathrm{mm}$ (R4)(Wang et al., 2014)分为 4 个径级。将解析后 的各部分分别称质量, 并测量每个径级根长, 两端 直径。木桩采样时, 先除去桩头 $5 \mathrm{~cm}$, 再截取厚度为 $5 \mathrm{~cm}$ 的圆盘, 将心材与树皮剥离, 分别称质量后带 
表1 研究样地基本概况

Table 1 The basic information of sampling plots

\begin{tabular}{|c|c|c|c|c|c|c|}
\hline $\begin{array}{l}\text { 样地 } \\
\text { Sampling plot }\end{array}$ & $\begin{array}{c}\text { 坡向/坡度 } \\
\text { Aspect/Slope }\left(^{\circ}\right)\end{array}$ & $\begin{array}{c}\text { 伐桩密度 } \\
\text { Stump density } \\
\left(\text { 株. } \cdot \mathrm{hm}^{-2}\right)\end{array}$ & $\begin{array}{c}\text { 根桩直径(平均值 } \pm \text { 标准误差) } \\
\text { Stump diameter (mean } \pm S E) \\
(\mathrm{cm})\end{array}$ & $\begin{array}{l}\text { 土壤 } \mathrm{pH} \text { 值 } \\
\mathrm{pH} \text { value }\end{array}$ & $\begin{array}{c}\text { 土壤容重 } \\
\text { Soil bulk density } \\
\left(\mathrm{g} \cdot \mathrm{cm}^{-3}\right)\end{array}$ & $\begin{array}{c}\text { 土壤有机质含量 } \\
\text { Soil organic matter } \\
\text { content }\left(\mathrm{g} \cdot \mathrm{kg}^{-1}\right)\end{array}$ \\
\hline S1 & NW/21 & 2050 & $16.4 \pm 0.48$ & 4.16 & 1.42 & 29.92 \\
\hline S2 & NW/18 & 2315 & $15.9 \pm 0.65$ & 4.14 & 1.39 & 28.96 \\
\hline S3 & NW/20 & 2100 & $17.2 \pm 0.53$ & 4.17 & 1.46 & 27.64 \\
\hline S4 & NW/21 & 2070 & $16.6 \pm 0.44$ & 4.14 & 1.40 & 27.44 \\
\hline S5 & NW/17 & 2405 & $15.6 \pm 0.56$ & 4.15 & 1.44 & 28.35 \\
\hline S7 & NW/20 & 2150 & $16.2 \pm 0.39$ & 4.16 & 1.41 & 27.43 \\
\hline S8 & NW/19 & 2190 & $16.4 \pm 0.41$ & 4.16 & 1.43 & 27.49 \\
\hline S9 & NW/20 & 2130 & $16.3 \pm 0.47$ & 4.18 & 1.45 & 27.64 \\
\hline S10 & NW/18 & 2350 & $15.9 \pm 0.62$ & 4.16 & 1.42 & 28.23 \\
\hline S11 & NW/19 & 2200 & $16.1 \pm 0.32$ & 4.15 & 1.44 & 28.06 \\
\hline S12 & NW/20 & 2085 & $17.1 \pm 0.54$ & 4.15 & 1.43 & 28.62 \\
\hline S13 & NW/21 & 2070 & $16.7 \pm 0.29$ & 4.16 & 1.39 & 29.26 \\
\hline S14 & NW/20 & 2125 & $16.8 \pm 0.51$ & 4.15 & 1.42 & 30.46 \\
\hline S15 & NW/17 & 2380 & $15.8 \pm 0.48$ & 4.15 & 1.40 & 31.45 \\
\hline
\end{tabular}

回; 根桩采样时, 分别在根桩的上部、中部、下部 截取样品, 称量后带回。将测量过的粗根全部带回。

\section{3 室内分析测定}

将带回实验室的样品, 采用水置换法测定树桩 各部分的体积, 计算树桩密度。 $70{ }^{\circ} \mathrm{C}$ 下烘干树桩, 测定树桩的干质量和含水率。

单位面积树桩的储量=树桩各部分质量的平均 值 $\times$ 样地内树桩数/样地面积

密度 $=$ 干质量 $/$ 体积 $\left(\mathrm{g} \cdot \mathrm{cm}^{-3}\right)$

含水率 $(\%)=($ 鲜质量 $-干$ 质量 $)$ 鲜质量 $\times 100 \%$

基于Olson (1963)的分解模型, 采用下式计算 根桩的分解速率 $(K)$ :

$$
K=\left(\ln \left(Y_{o}\right)-\ln \left(Y_{t}\right)\right) / t
$$

式中 $t$ 为根桩保留在林地上的时间, $Y_{o}$ 为当年采伐树 桩的密度, $Y_{t}$ 为 $t$ 时的根桩密度。

\section{4 数据处理与统计分析}

数据统计分析采用SPSS 20.0和Excel 2003软件 完成。采用单因素方差分析(one-way ANOVA)和最 小显著差异法 $(L S D)$ 检验不同分解时间树桩各部储 量、密度的差异, 显著性水平设定为 $p=0.05$ 。

\section{2 结果}

\section{1 伐桩储量}

随着分解时间增加，木桩的储量在4-36 t· hm ${ }^{-2}$ 范围内变化, 呈先迅速降低后缓慢降低的趋势
(图1), 表明伐桩分解释放了大量的有机物质与养 分, 这对于维持土壤肥力和生态系统生物元素循环 具有重要意义。经过15年的分解，木桩的储量由 $36.52 \mathrm{t} \cdot \mathrm{hm}^{-2}$ 逐渐降低到8.16 t. $\mathrm{hm}^{-2}$, 且变化极显著 $(p<0.01)$ 。SW、B、SR也呈同样的变化规律, SW储 量降低显著 $(p<0.05)$, SR储量降低极显著 $(p<0.01)$, 但B储量降低不显著 $(p>0.05)$ (图2)。

随着分解的进行, SW、B、SR储量在整个树桩 中所占的比例逐渐变化。树皮在其中所占的比例显 著增大, 由 $1.604 \%$ 增加到 $10.845 \%$ 。木桩的比例也由 $14.337 \%$ 增加到 $38.498 \%$, 而根桩的比例由 $84.059 \%$ 减小到 $50.657 \%$ (图3)。

根桩在分解过程中, 储量在 $1-22 \mathrm{t} \cdot \mathrm{hm}^{-2}$ 范围内 变化, 其储量变化与木桩储量变化大致类似, 但有 一个增加过程, 呈先增加后迅速降低再缓慢降低的 趋势, 根桩的储量由17.49 $\mathrm{t} \cdot \mathrm{hm}^{-2}$ 逐渐降低到4.91 $\mathrm{t} \cdot \mathrm{hm}^{-2}$ 。单因素方差分析表明, 伐桩粗根储量随着分 解的进行变化极显著 $(p<0.01)$ (图4)。

随分解时间的增加, R1、R2储量一直缓慢降低, $\mathrm{R} 1$ 储量从0.62 $\mathrm{t} \cdot \mathrm{hm}^{-2}$ 减少到 $0.02 \mathrm{t} \cdot \mathrm{hm}^{-2}, \mathrm{R} 2$ 储量从 $1.75 \mathrm{t} \cdot \mathrm{hm}^{-2}$ 减少到 $0.17 \mathrm{t} \cdot \mathrm{hm}^{-2}$ 。 R1、R2径级根的储量 变化极显著 $(p<0.01)$, 而R3、 R4径级根的储量变化 趋势与粗根的整体储量变化趋势一致, 都是先增加 后迅速降低再缓慢降低, R3 储量从4.26 t $\cdot \mathrm{hm}^{-2}$ 增加 到6.17 t $\cdot \mathrm{hm}^{-2}$, 经分解减少到 $2.30 \mathrm{t} \cdot \mathrm{hm}^{-2}, \mathrm{R} 4$ 的储量 


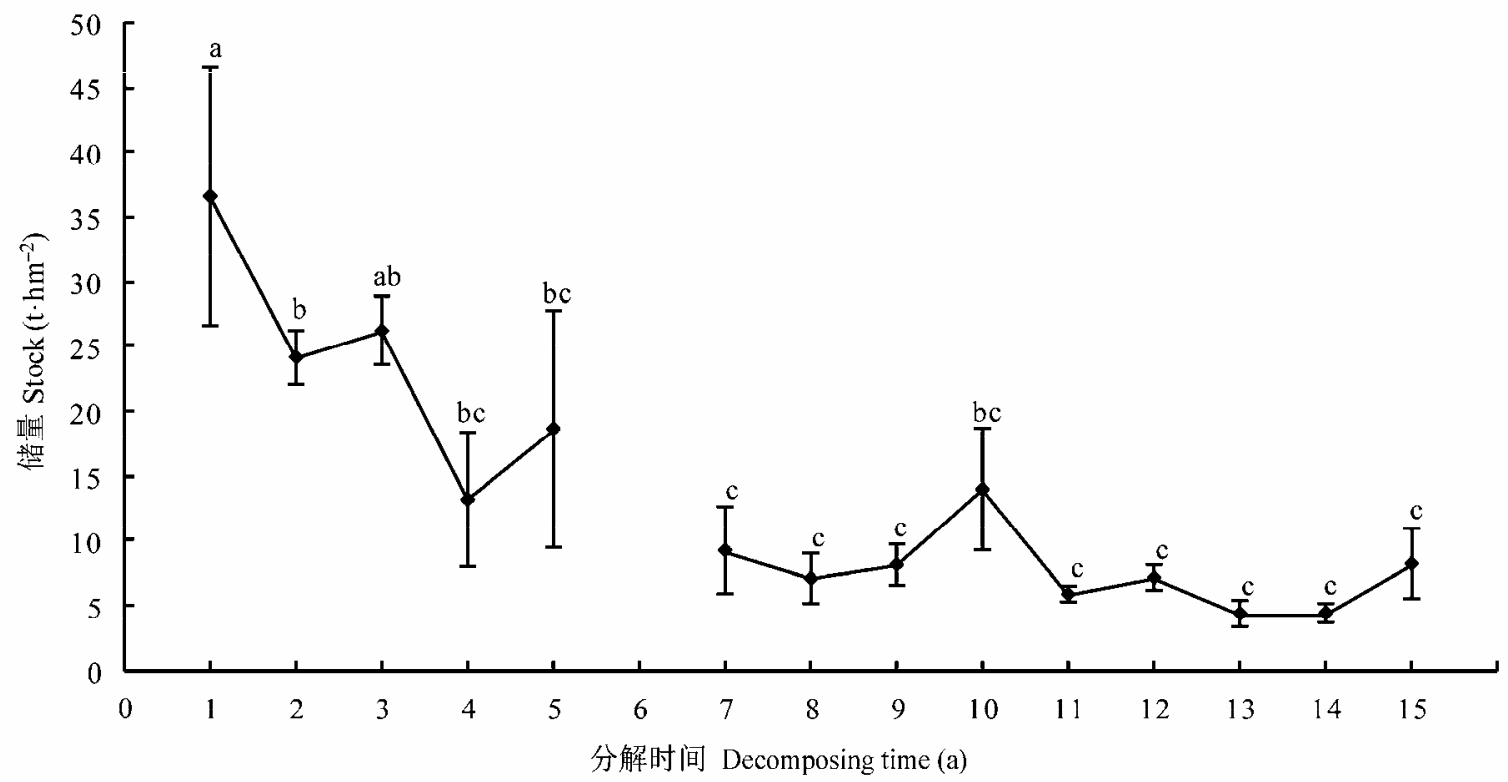

图1 马尾松人工林伐桩分解序列的储量变化(平均值标准误差, $n=3$ )。不同小写字母表示不同分解年限间差异显著 $(p<0.05)$ 。 Fig. 1 Changes in stump stocks of Pinus massoniana plantations across a decomposition series (mean $\pm S E, n=3$ ). Different lowercase letters mean the level of significant differences among different decomposition years $(p<0.05)$.

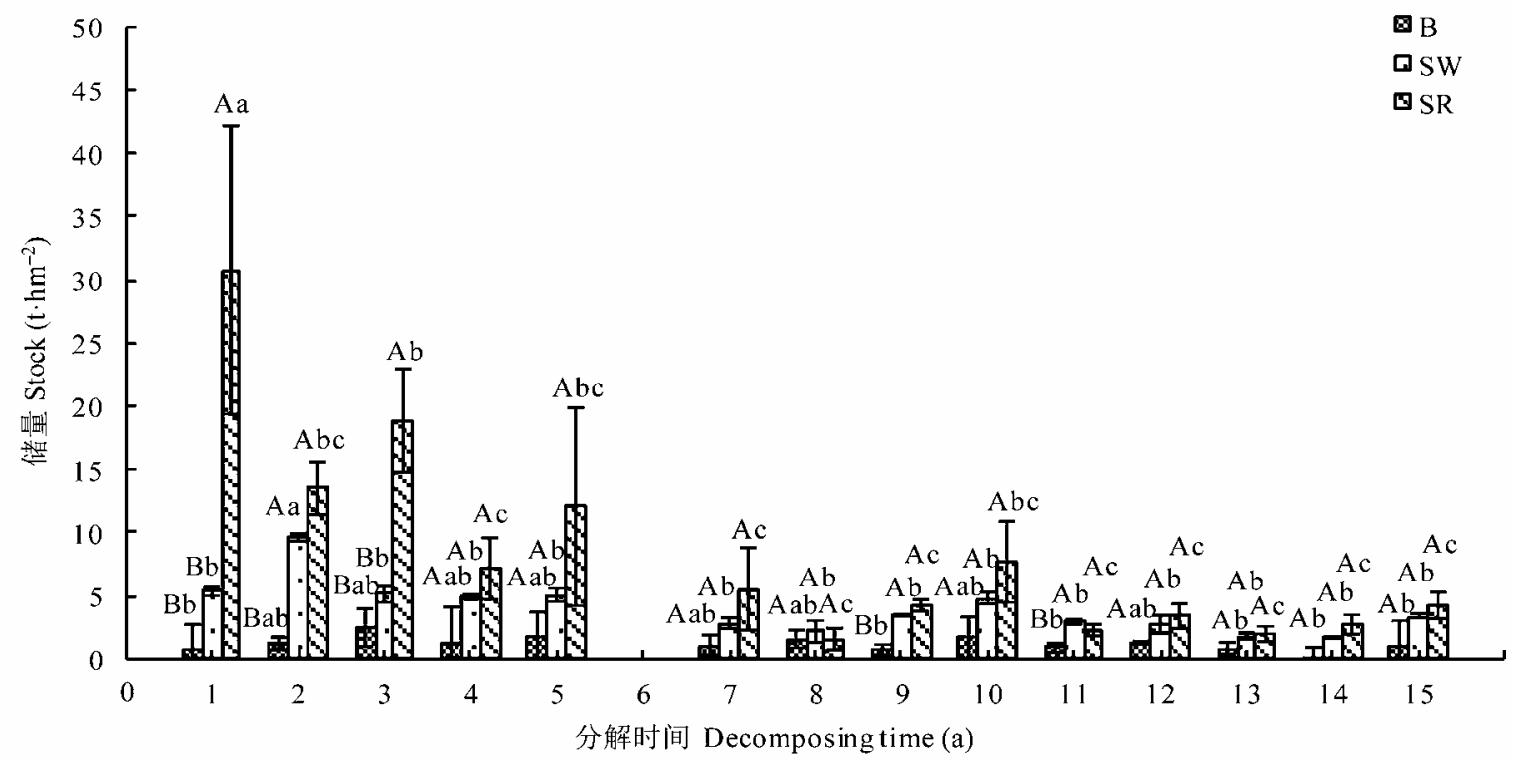

图2 马尾松人工林伐桩的木桩、树皮和根桩储量随分解过程的变化(平均值沶准误差, $n=3$ )。不同小写字母表示不同分解 年限间差异显著 $(p<0.05)$, 不同大写字母表示同一分解时间不同部位间差异显著 $(p<0.05)$ 。 , 树皮; SR, 根桩; SW, 木桩。

Fig. 2 Changes in stump wood, bark and stump root stocks with stump decomposition in the Pinus massoniana plantations (mean \pm $S E, n=3)$. Different lowercase letters mean the level of significant differences among different decomposition years $(p<0.05)$, and different uppercase letters indicate the level of significant differences among different stump parts $(p<0.05)$. B, bark; SR, stump root; SW, stump wood.

从10.87 t $\cdot \mathrm{hm}^{-2}$ 增加到 $17.78 \mathrm{t} \cdot \mathrm{hm}^{-2}$, 随着分解的进行 降低到 $2.41 \mathrm{t} \cdot \mathrm{hm}^{-2}$, 且R3径级的储量变化极显著 $(p<0.01)$, R4径级的储量变化显著 $(p<0.05)$ (图5)。 同时, 各径级根的储量R4 > R3 > R2 > R1, 而且 R3、R4的储量明显大于R1、R2的储量, 说明R3、
R4径级的根对粗根系统储量的贡献大, 它们的变化 对粗根储量的变化较R1、R2影响大。

\section{2 伐桩密度变化}

随分解时间的增加, SW、B、SR的密度呈降低 的趋势, 且逐渐趋于稳定(图6)。经15年的分解, SW 的 


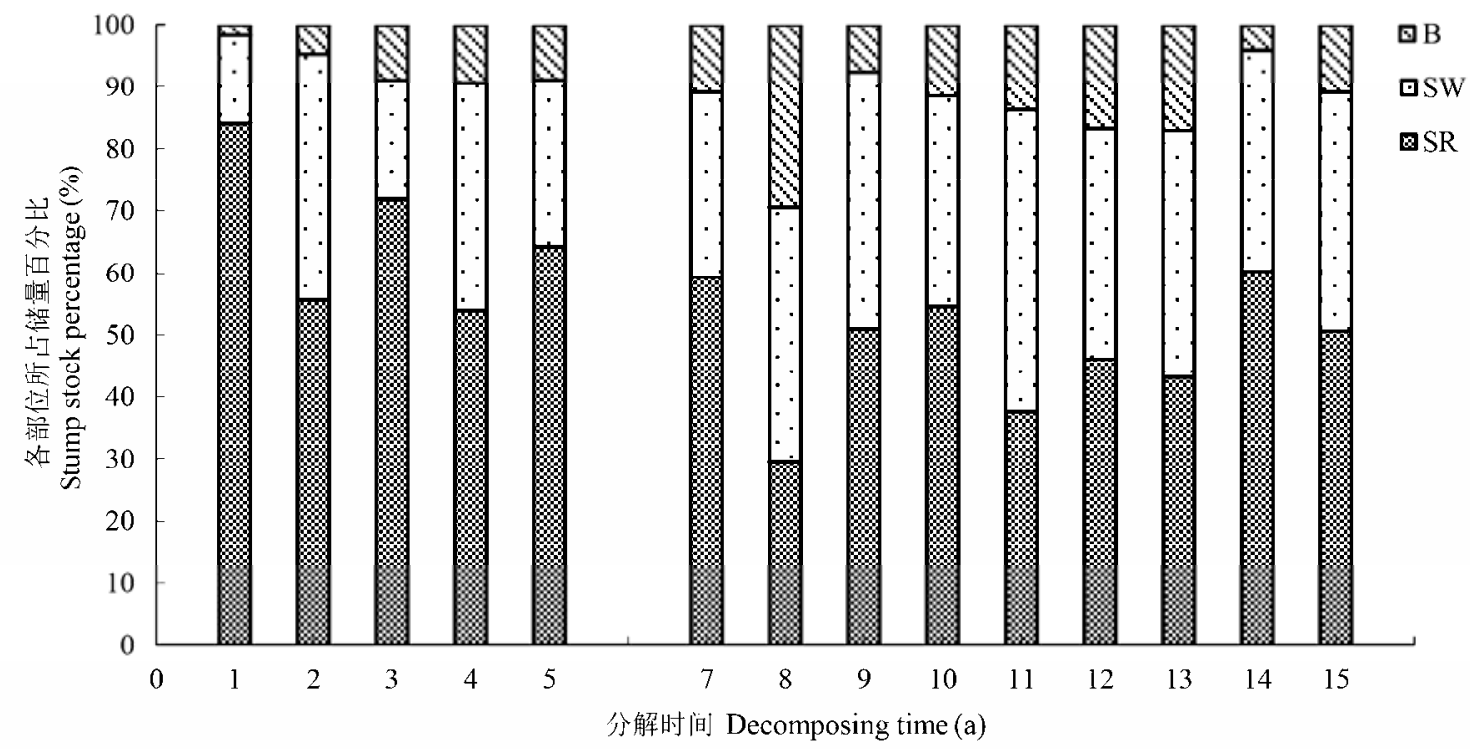

图3 马尾松人工林伐桩不同部位的储量比例随分解过程的变化(平均值标准误差, $n=3$ )。 $\mathrm{B}$, 树皮; SR, 根桩; SW, 木桩。

Fig. 3 Changes in the relative ratios among stump wood, stump bark and stump root with stump decomposition in the Pinus massoniana plantations (mean $\pm S E$ ). B, bark; SR, stump root; SW, stump wood.

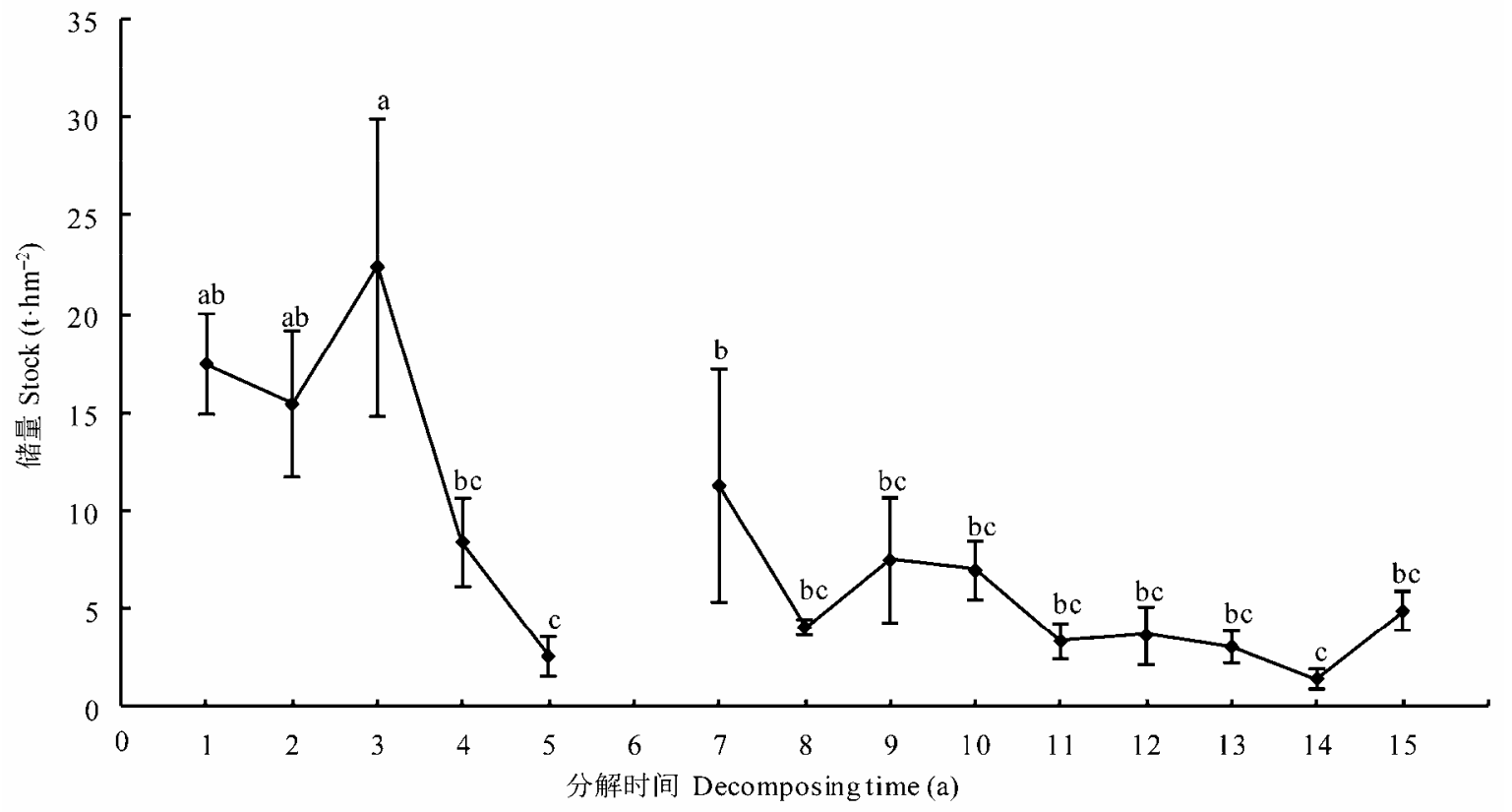

图4 马尾松伐桩分解过程中根桩储量的变化(平均值标准误差, $n=3$ )。不同小写字母表示不同分解年限间差异显著 $(p<0.05)$ 。 Fig. 4 Changes in stump root stocks with stump decomposition in the Pinus massoniana plantations (mean $\pm S E$, $n=3$ ). Different lowercase letters mean the level of significant differences among different decomposition years $(p<0.05)$.

密度由未分解时的 $0.89 \mathrm{~g} \cdot \mathrm{cm}^{-3}$ 降低到 $0.36 \mathrm{~g} \cdot \mathrm{cm}^{-3}, \mathrm{SR}$ 的密度由未分解时的 $0.60 \mathrm{~g} \cdot \mathrm{cm}^{-3}$ 降低到 $0.40 \mathrm{~g} \cdot \mathrm{cm}^{-3}$ 。 而B的密度呈现缓慢降低的趋势, 经15年的分解由 未分解时的 $0.47 \mathrm{~g} \cdot \mathrm{cm}^{-3}$ 降低到 $0.32 \mathrm{~g} \cdot \mathrm{cm}^{-3}$ 。B密度趋 于稳定的时间比 SW 和SR早, B分解到第5年后密度 就趋于稳定, 而SW和SR分解到第8年以后密度才逐
渐趋于稳定(图6)。

随分解时间的增加，根桩内营养物质被逐渐分 解, 不同径级根系的密度呈降低趋势并逐渐趋于稳 定(图7)。单因素方差分析表明, 不同径级根系在分 解初期的密度与其他时间分解密度的差异显著 $(p<$ 0.05)。在根桩分解初期, R1、R2和R3径级的密度缓 


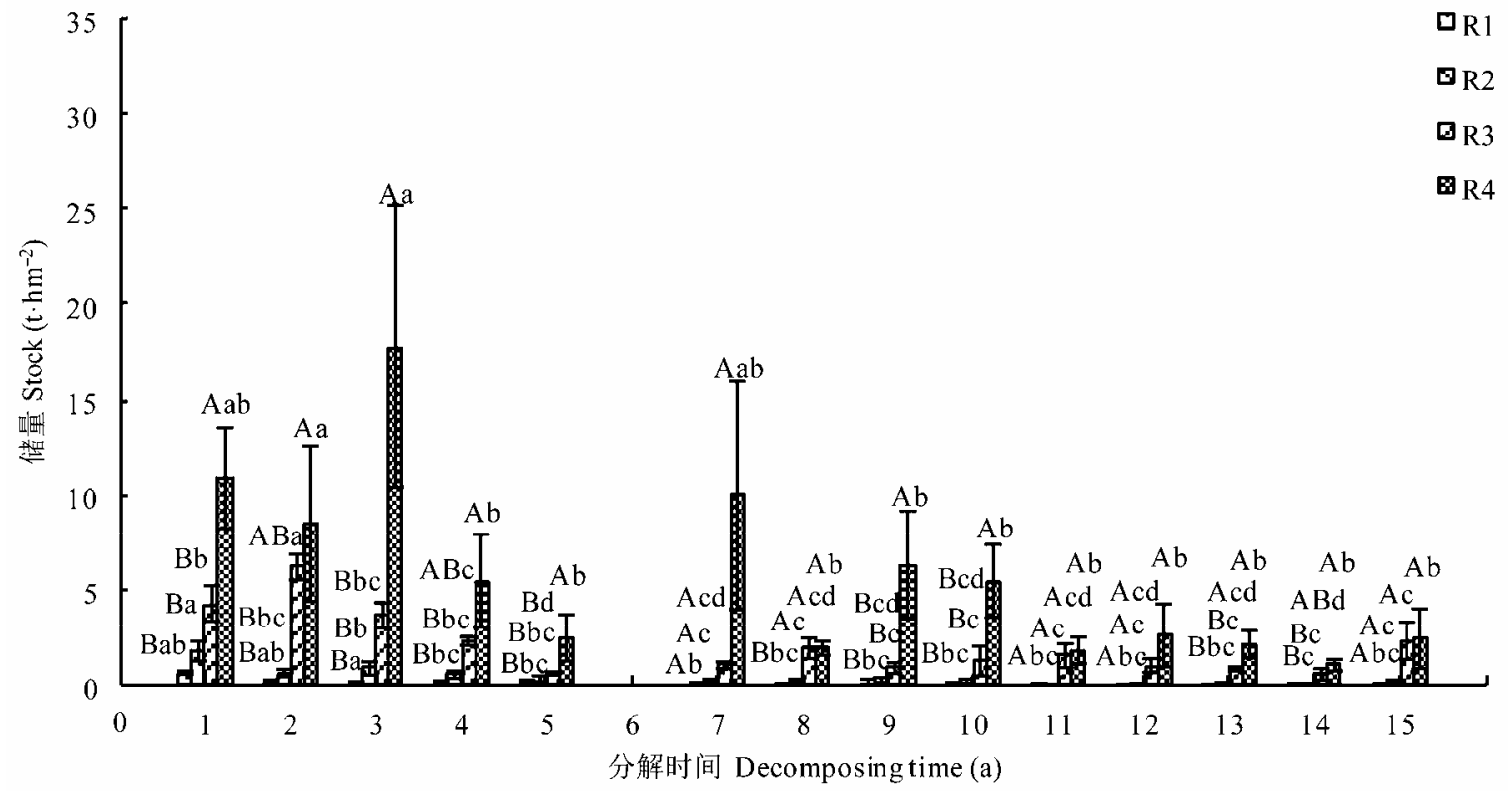

图5 马尾松人工林不同径级根分解过程中的储量变化(平均值土标准误差, $n=3$ )。不同小写字母表示不同分解年限间差异显 著 $(p<0.05)$, 不同大写字母表示同一分解时间不同部位间差异显著 $(p<0.05)$ R $1,0 \mathrm{~mm}<$ 径级 $\leqslant 10 \mathrm{~mm}$; $\mathrm{R} 2,10 \mathrm{~mm}<$ 径级 $\leqslant$ $25 \mathrm{~mm}$; R3, $25 \mathrm{~mm}$ <径级 $\leqslant 100 \mathrm{~mm})$; R4, 径级>100 mm。

Fig. 5 Changes in different class root decomposition stocks with stump decomposition in the Pinus massoniana plantations (mean \pm $S E, n=3)$. Different lowercase letters mean the level of significant differences among different decomposition years $(p<0.05)$, and different uppercase letters indicate the level of significant differences among different stump parts $(p<0.05)$. R1, 0 mm $<$ diameter $\leqslant 10 \mathrm{~mm}$; R2, $10 \mathrm{~mm}<$ diameter $\leqslant 25 \mathrm{~mm}$; R3, $25 \mathrm{~mm}<$ diameter $\leqslant 100 \mathrm{~mm}$; R4, diameter $>100 \mathrm{~mm}$.

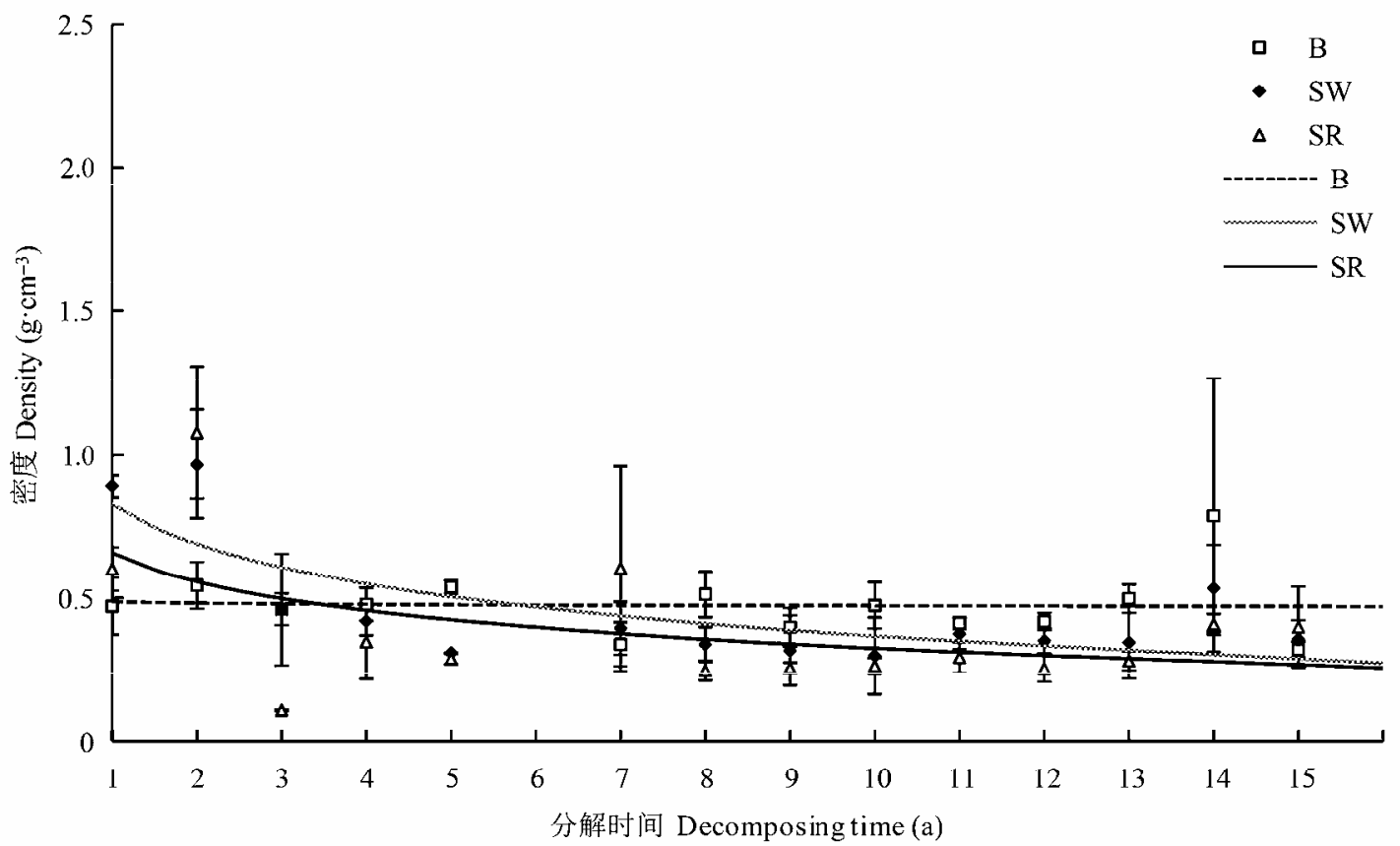

图6 马尾松人工林伐桩的木桩、树皮和根桩密度随分解过程的变化(平均值土标准误差, $n=3$ )。 B, 树皮; SR, 根桩; SW, 木桩。 Fig. 6 Changes in stump wood, bark and stump root density with stump decomposition in the Pinus massoniana plantations (mean \pm $S E, n=3)$. B, bark; SR, stump root; SW, stump wood.

慢降低，而R4径级的密度迅速减小。从采伐1年到15 年的伐桩密度来看, R1径级的密度由 $0.68 \mathrm{~g} \cdot \mathrm{cm}^{-3}$ 降 低到 $0.21 \mathrm{~g} \cdot \mathrm{cm}^{-3}$, R2 径级的密度由 $0.58 \mathrm{~g} \cdot \mathrm{cm}^{-3}$ 降低到
$0.31 \mathrm{~g} \cdot \mathrm{cm}^{-3}, \mathrm{R} 3$ 径级的密度由 $0.59 \mathrm{~g} \cdot \mathrm{cm}^{-3}$ 降低到 0.29 $\mathrm{g} \cdot \mathrm{cm}^{-3}$, 且在采伐 $5-7$ 年后变化趋于稳定, 而 $\mathrm{R} 4$ 径级 的密度由 $1.66 \mathrm{~g} \cdot \mathrm{cm}^{-3}$ 降低到 $0.28 \mathrm{~g} \cdot \mathrm{cm}^{-3}$, 并且还有 


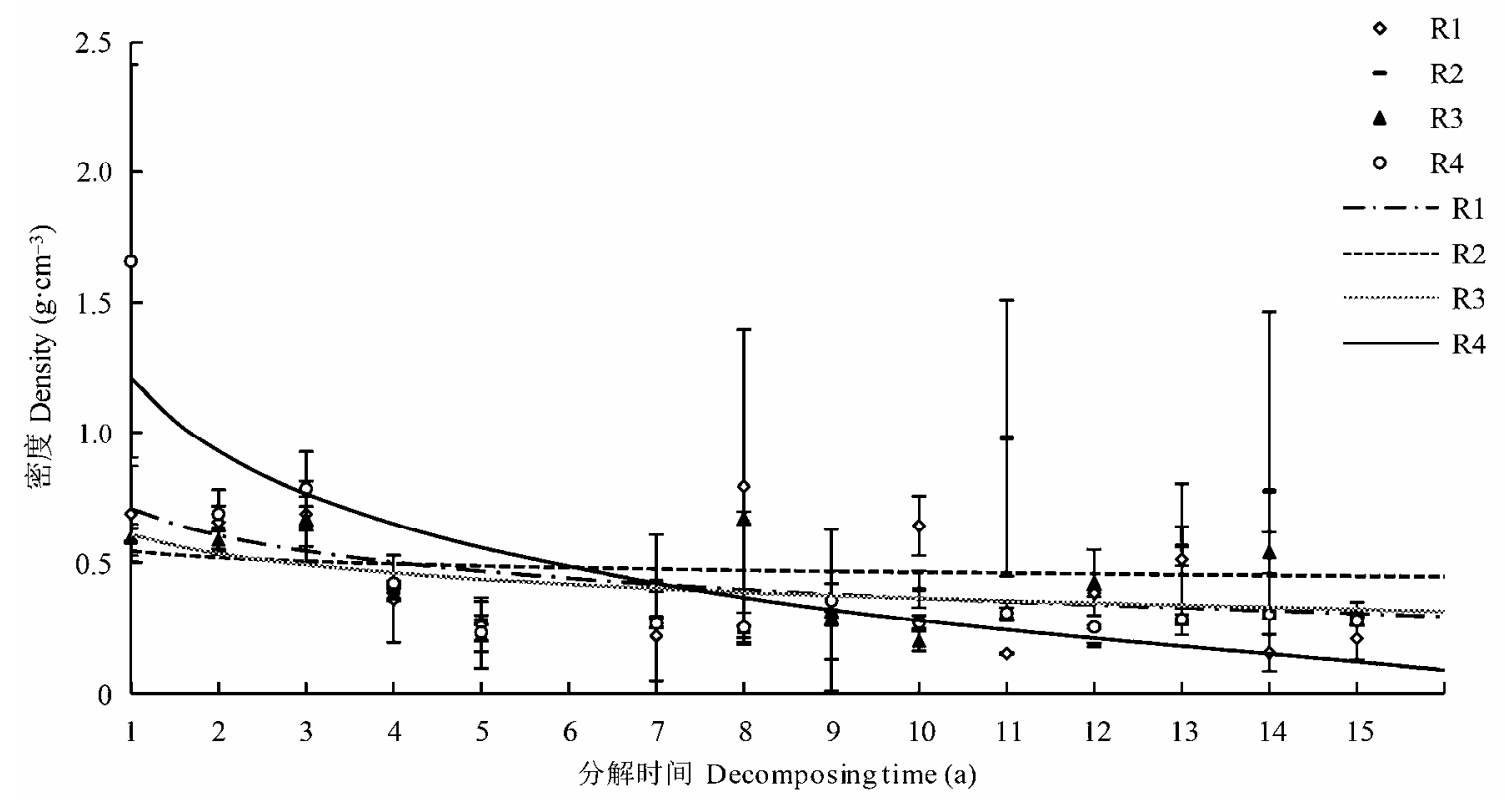

图7 马尾松人工林不同径级根分解过程中的密度变化(平均值 \pm 标准误差, $n=3$ )。 R1, $0 \mathrm{~mm}<$ 径级 $\leqslant 10 \mathrm{~mm} ; \mathrm{R} 2,10 \mathrm{~mm}<$ 径 级 $\leqslant 25 \mathrm{~mm}$; R3, $25 \mathrm{~mm}$ <径级 $\leqslant 100 \mathrm{~mm}$ ); R4, 径级> $100 \mathrm{~mm}$ 。

Fig. 7 Changes in different class root decomposition density with stump decomposition in the Pinus massoniana plantations (mean \pm $S E, n=3)$. R1, $0 \mathrm{~mm}<$ diameter $\leqslant 10 \mathrm{~mm}$; R2, $10 \mathrm{~mm}<$ diameter $\leqslant 25 \mathrm{~mm}$; R3, $25 \mathrm{~mm}<$ diameter $\leqslant 100 \mathrm{~mm}$; R4, diameter $>$ $100 \mathrm{~mm}$.

继续降低的趋势。与采伐1年后的各径级根系密度相 比, R1、R2、R3和R4分别大约分解为原来的 $31 \%$ 、 $53 \% 、 49 \% 、 17 \%$ 。

拟合树桩分解过程中不同部位的密度 $(Y)$ 与时 间 $(t)$ 的对数函数方程 (表 2$) 反$ 映了马尾松伐桩不同 部位密度变化, 可以为研究马尾松伐桩整个分解过 程的分解特征提供依据。

表2 树桩分解过程中不同部位的密度 $(Y)$ 与时间 $(t)$ 的对数函数方程

Table 2 The density $(Y)$ of different components and the logarithmic function equation of time $(t)$ in stump decomposition process

\begin{tabular}{lcc}
\hline $\begin{array}{l}\text { 树桩的部位 } \\
\text { Parts of the stump }\end{array}$ & $\begin{array}{c}\text { 对数函数方程 } \\
\text { Logarithmic function } \\
\text { equation }\end{array}$ & $r$ \\
\hline 树皮 Barks & $Y=-0.0051 \ln (t)+0.4778$ & 0.0013 \\
木桩 Stump wood & $Y=-0.1989 \ln (t)+0.8153$ & 0.5679 \\
根桩 Stump root & $Y=-0.1444 \ln (t)+0.6522$ & 0.2379 \\
$0 \mathrm{~mm}$ <径级 Diameter $\leqslant 10 \mathrm{~mm}$ & $Y=-0.1470 \ln (t)+0.6937$ & 0.2714 \\
$10 \mathrm{~mm}$ <径级 Diameter $\leqslant 25 \mathrm{~mm}$ & $Y=-0.0352 \ln (t)+0.5470$ & 0.0161 \\
$25 \mathrm{~mm}$ <径级 Diameter $\leqslant 100 \mathrm{~mm})$ & $Y=-0.1043 \ln (t)+0.5951$ & 0.2415 \\
径级 Diameter > $100 \mathrm{~mm})$ & $Y=-0.4042 \ln (t)+1.2127$ & 0.7241 \\
\hline
\end{tabular}

\section{3 伐桩分解特征}

伐桩分解过程中, SW、B、SR的分解速率随分 解时间的增加先增大后减小且逐渐趋于一致(图8)。
SW的分解速率整体大于B和SR。分解初期, SW的分 解速率变化按照慢 $\rightarrow$ 快 $\rightarrow$ 慢节奏增加, 到第 4 年达 到最大值, 而 $\mathrm{B}$ 和 $\mathrm{SR}$ 的分解速率变化呈现缓慢增加 趋势，分别到第6年和第7年达到最大值。

在分解初期, R1、R2和R3有一个分解特别缓慢 的停滞阶段, 从第2年前中期分解速率开始增大, 分 别在分解第 7 年、第 9 年、第 4 年增大到整个分解过程 中分解速率的最大值 $0.22 、 0.19 、 0.14$, 此后它们的 分解速率分别逐渐降低到 $0.08 、 0.04 、 0.05$, 并趋于 稳定; R4 在分解初期没有明显的停滞阶段, 而是分 解速率迅速增大，在分解第3年中期达到最大值 0.95 , 此后分解速率迅速降低, 从第7年后分解速率 就缓慢降低到 0.26 , 且逐渐趋于稳定(图9)。

\section{3 讨论和结论}

理论上, 采伐时间越久, 人工林的伐桩储量越 小(杨方方等, 2009; 张修玉等, 2009; 袁杰等, 2012)。本研究表明, 分解15年后, 马尾松伐桩的储 量由 $58 \mathrm{t} \cdot \mathrm{hm}^{-2}$ 降低到 $5 \mathrm{t} \cdot \mathrm{hm}^{-2}$, 且木桩、根桩和不同 径级的根系均表现出相似的变化趋势。这意味着, 在物理、化学和生物因子的综合作用下, 伐桩将归 还大量碳和养分到土壤库中(杨玉盛等, 2003), 保持 


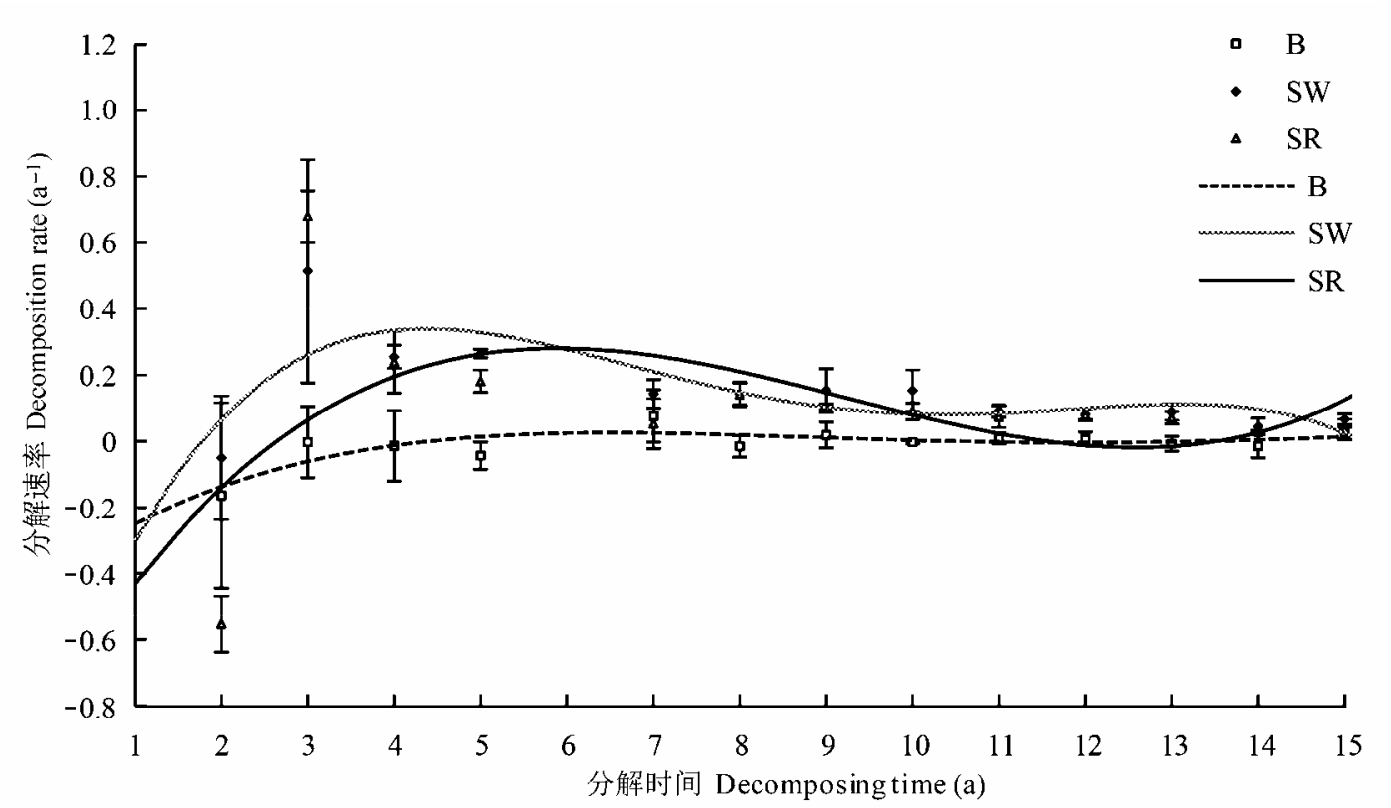

图8 马尾松人工林伐桩的木桩、树皮和根桩分解速率随分解过程的变化(平均值土标准误差, $n=3$ )。 B, 树皮; SR, 根桩; SW, 木桩。

Fig. 8 Changes in stump wood, bark and stump root decomposition rate with stump decomposition in the Pinus massoniana plantations (mean $\pm S E, n=3$ ). B, bark; SR, stump root; SW, stump wood.

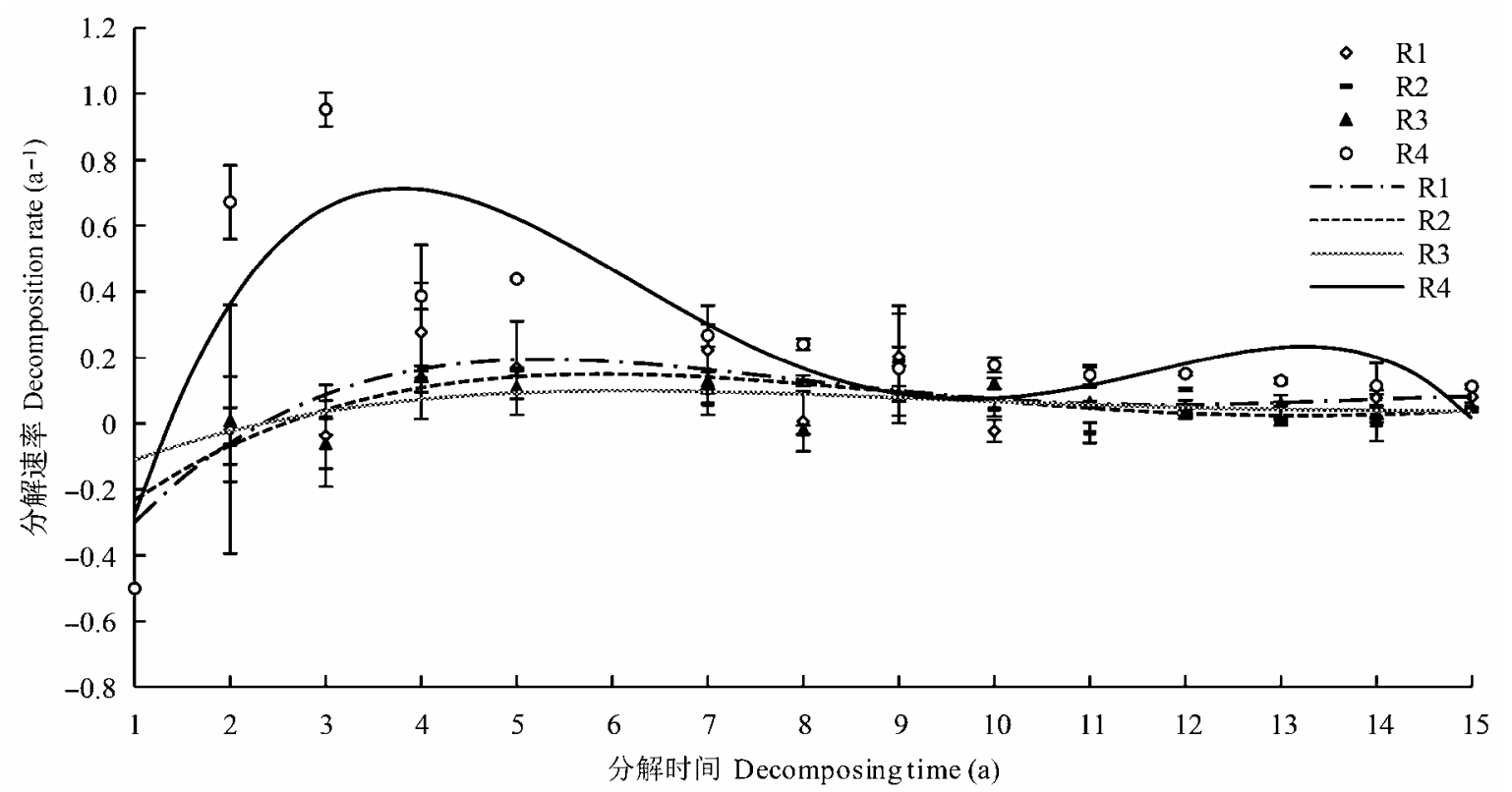

图9马尾松人工林不同径级根分解过程中的分解速率变化(平均值 \pm 标准误差, $n=3$ )。 R1, $0 \mathrm{~mm}<$ 径级 $\leqslant 10 \mathrm{~mm} ; \mathrm{R} 2,10 \mathrm{~mm}<$ 径级 $\leqslant 25 \mathrm{~mm}$; R3, $25 \mathrm{~mm}$ <径级 $\leqslant 100 \mathrm{~mm}$ ); R4, 径级> $100 \mathrm{~mm}$ 。

Fig. 9 Changes in different class root decomposition rate with stump decomposition in the Pinus massoniana plantations (mean \pm $S E, n=3)$. R1, $0 \mathrm{~mm}<$ diameter $\leqslant 10 \mathrm{~mm}$; R2, $10 \mathrm{~mm}<$ diameter $\leqslant 25 \mathrm{~mm}$; R3, $25 \mathrm{~mm}<$ diameter $\leqslant 100 \mathrm{~mm}$; R4, diameter > $100 \mathrm{~mm}$.

了土壤肥力, 促进了人工林生态系统的物质循环与 能量循环。其中, 根桩的储量降低速度高于木桩, 不 同径级的根系相比, 径级越大, 储量变化越大。这表 明, 树皮中不利于微生物分解的木质素、纤维素等 多酚类物质含量高, 所以变化规律不明显( 常晨晖
等, 2015)。木桩与根桩的营养物质成分相似, 但根 桩更接近于土壤, 不仅有利于土壤动物的作用, 而 且有利于微生物的附着, 同时能更快地将营养物质 释放到土壤中, 所以根桩的储量变化大。径级小的 根微生物定植与着生的滞后时间比较久, 这也许是 
由于非近地面土壤动物种群少, 作用弱, 而径级大 的根本身生物量大, 适合微生物利用分解的物质比 重大。然而, 伐桩的储量还受到树木基径和采伐高 度等影响。与其他地区森林的CWD储量相比, 马尾 松人工林CWD储量总体偏高, 高于温带地区东北 长白山云冷杉倒木储量(杨丽暳等, 2002), 高于西双 版纳热带季节雨林(宋泽伟和唐建维, 2008)、亚热带 武夷山甜槠(Castanopsis eyrei)林(李凌浩等, 1996)、 鼎湖山阔叶林(唐旭利等, 2003)、秦岭巴山冷杉 (Abies fargesii)林(李凌浩等, 1998)、大明山阔叶林 (温琳华等, 2010)、小陇山锐齿栎(Quercus aliena var. acuteserata)林(何帆等, 2011), 但低于川西高山森林 倒木储量(肖酒等, 2014)。本研究中, 伐桩的木桩储 量、根桩储量在分解第二年降低, 第三年升高, 之后 呈现逐渐下降的趋势。原因可能是分解第三年, 即 2011年采伐的马尾松人工林生长相对较好、基径较 大。具体原因尚待进一步调查研究。

随着分解时间增加, 整个伐桩系统及其组分的 密度均表现为降低的趋势, 但由于其质量和对环境 的响应差异, 不同组分的密度变化明显不同。相对 于其他组分, 树皮包裹于伐桩系统之外, 最先受到 土壤生物的侵入, 也最易受环境变化的影响。因此, 树皮密度趋于稳定的时间早。伐桩中木桩、根桩及 不同径级的根中, 有利于微生物分解的养分元素 (如: N、P、K 和有机质等)被微生物分解利用, 难分 解化学组分(如: 纤维素、木质素和单宁等)在组织里 累积, 所以伐桩各组分的密度逐渐降低并趋于稳 定。但由于径级大的根分解初期生物量大, 分解速 率大, 所以密度变化大, 经 15 年分解, 密度也没有 趋于稳定的趋势。

马尾松人工林伐桩不同组分的腐烂速率存在较 大差异。这是因为能影响微生物生长与发育的因子 就能影响伐桩的分解, 分解初期某些土壤动物也起 一定作用(Stohlgren, 1988)。这些影响因子包括有机 质本身的质地和外界理化环境。有机质本身的质地 包括化学属性(C、能源、养分和调节因子)和物理属 性(表面性质、硬度、大小等)两个主要方面; 外界理 化环境包括温度、湿度、 $\mathrm{pH}$ 值、淋洗及其他因子等。 因此, 马尾松人工林伐桩不同组分的分解差异与其 本身的化学性质、物理结构及所处的外界环境有关, 且不同植物残体的分解速率也会相差很大。例如, Chen等(2001)对美国俄勒冈州几种树种木质树根分
解的研究发现, 树种之间的分解速率相差很大。同 一片林分中云杉(Picea sitchensis)树根的分解常数 在 0.016-0.021之间, 而加州铁杉 (Tsuga heterophylla)树根的分解常数在0.033-0.049之间。在另一 片林分中, 黑松(Pinus contorta)树根的分解常数在 0.025-0.030之间, 而北美黄松(Pinus ponderosa)树 根的分解常数在0.073-0.077之间。黄志群等(2005) 研究了连栽杉木(Cunninghamia lancelata)林中伐桩 的分解过程, 其分解常数为 $0.027 \pm 0.004$ 。本研究表 明, 马尾松人工林木桩与根桩的分解常数分别为 $0.061 \pm 0.021 、 0.027 \pm 0.005$, 分解相对较慢, 这可 能与其较高的 C/N比有关(Blumfield et al., 2004)。研 究结果与伐桩的实际分解过程还存在一定偏差, 但 基本上能反映马尾松人工林伐桩分解过程中各组分 的储量变化与分解特征, 不仅为马尾松伐桩分解过 程中营养元素变化与影响伐桩分解因素的研究提供 了依据, 而且也可以对马尾松人工林的经营与调控 发挥一定的参考作用, 但由于CWD在林地表面存 留时间相对较长(Hood et al., 2004), 其存在状态及 其生态功能对森林生态系统碳循环的影响还有待于 长期深入的追踪研究。

基金项目 国家“十二五”科技支撑计划(2011BAC09B05)、国家自然科学基金(31370628)、四川省杰出 青年学术与技术带头人培育项目(2012JQ0008)和中 国博士后科学基金(2013M540714和2012T50782)。

致谢感谢肖酒在采样和实验工作中给予的帮助。

\section{参考文献}

Blumfield TJ, Xu ZH, Mathers NJ, Saffigna PG (2004). Decomposition of nitrogen. Soil Science Society of America Journal, 68, 1751-1761.

Chang CH, Wu FZ, Yang WQ, Tan B, Xiao S, Li J, Gou XL (2015). Changes in log quality at different decay stages in an alpine forest. Chinese Journal of Plant Ecology, 39, 14-22. (in Chinese with English abstract) [常晨晖, 吴福 忠, 杨万勤, 谭波, 肖酒, 李俊, 苟小林 (2015). 高寒森 林倒木在不同分解阶段的质量变化. 植物生态学报, 39, 14-22.]

Chen H, Harmon ME, Griffiths RP (2001). Decomposition and nitrogen release from decomposing woody roots in coniferous forests of the Pacific Northwest: A chronosequence approach. Canadian Journal of Forest Research, 31, 246-260.

Cleary MR, Arhipova N, Morrison DJ, Thomsen IM, Sturrock RN, Vasaitis R, Gaitnieks T, Stenlid J (2013). Stump removal to control root disease in Canada and Scandinavia: 
A synthesis of results from long-term trials. Forest Ecology and Management, 290, 5-14.

Harmon ME, Franklin JF, Swanson FJ, Sollins P, Gregory SV, Lattin JD, Anderson NH, Cline SP, Aumen NG, Sedell JR, Lienkaemper GW, Cromack K Jr, Cummins KW (1986). Ecology of coarse woody debris in temperate ecosystems. Advance in Ecological Research, 15, 133-302.

He F, Wang DX, Zhang SZ, Liu WZ, Shen YZ, Hu YN (2011). Reserves of litter and woody debris of two main forests in the Xiaolong Mountains, Gansu, China. Chinese Journal of Applied and Environmental Biology, 17, 46-50. (in Chinese with English abstract) [何帆, 王得祥, 张宋智, 刘文桢, 沈亚洲, 胡有宁 (2011). 小陇山林区主要森林 群落调落物及死木质残体储量. 应用与环境生物学报, 17, 46-50.]

Hood IA, Beets PN, Kimberley MO, Gardner JF, Oliver GR, Pearce S (2004). Colonisation of podocarp coarse woody debris by decomposer basidiomycete fungi in an indigenous forest in the central North Island of New Zealand. Forest Ecology and Management, 196, 311-325.

Hou P, Pan CD (2001). Coarse woody debris and its function in forest ecosystem. Chinese Journal of Applied Ecology, 12, 309-314. (in Chinese with English abstract) [侯平, 潘存 德 (2001). 森林生态系统中的粗死木质残体及其功能. 应用生态学报, 12, 309-314.]

Huang ZQ, Xu ZH, Boyd S, Williams D (2005). Chemical composition trend in Cunninghamia lancelata (Lamb.) Hook. stump decomposition process. Chinese Science Bulletin, 50, 2365-2369. (in Chinese) [黄志群, 徐志红, Sue Boyd, David Williams (2005). 连栽杉木(Cunninghamia lancelata (Lamb.) Hook.) 林中树桩分解过程中的化 学组分变化趋势. 科学通报, 50, 2365-2369.]

Justine MF, Yang WQ, Wu FZ, Tan B, Muhammad NK, Zhao YY (2015). Biomass stock and carbon sequestration in a chronosequence of Pinus massoniana plantations in the upper reaches of the Yangtze River. Forests, 6, 36653682.

Kang B, Liu SR, Cai DX, Lu LH (2009). Effects of Pinus massoniana plantation stand density on understory vegetation and soil properties. Chinese Journal of Applied Ecology, 20, 2321-2331. (in Chinese with English abstract) [康冰, 刘世荣, 蔡道雄, 卢立华 (2009). 马尾松人工林林分密 度对林下植被及土壤性质的影响. 应用生态学报, 20 , 2321-2331.]

Li LH, Dang GD, Wang TJ, Zhao LG (1998). Coarse woody debris in an Abies fargesii forest in the Qinling Mountains. Acta Phytoecologica Sinica, 22, 434-440. (in Chinese with English abstract) [李凌浩, 党高弟, 汪铁军, 赵雷刚 (1998). 秦岭巴山冷杉林粗死木质残体研究. 植物生态 学报, 22, 434-440.]

Li LH, Xing XR, Huang DM, Liu CD, He JY (1996). Storage and dynamics of coarse woody debris in Castanopsis eyrei forest of Wuyi Mountain, with some considerations for its ecological effects. Acta Phytoecologica Sinica, 20, 132143. (in Chinese with English abstract) [李凌浩, 邢雪荣, 黄大明, 刘出钿, 何建源 (1996). 武夷山甜槠林粗死木 质残体的咜量、动态及其功能评述. 植物生态学报, 20 , 132-143.]

Mo JM, Brown S, Peng SL, Kong GH, Zhang DQ, Zhang YC (2002). Role of understory plants on nutrient cycling of a restoring degraded pine forests in a MAB reserve of subtropical China. Acta Ecologica Sinica, 22, 1407-1413. (in Chinese with English abstract) [莫江明, Sandra Brown, 彭少麟, 孔国辉, 张德强, 张佑昌 (2002). 林下层植物 在退化马尾松林恢复初期养分循环中的作用. 生态学 报, 22, 1407-1413.]

Ols C, Victorsson J, Jonsell M (2013). Saproxylic insect fauna in stump on wet and dry soil: Implications for stump harvest. Forest Ecology and Management, 290, 15-21.

Olson JS (1963). Energy storage and the balance of producers and decomposers in ecological systems. Ecology, 2, 322-331.

Persson T (2013). Environmental consequences of tree-stump harvesting. Forest Ecology and Management, 290, 1-4.

Persson T, Lenoir L, Vegerfors B (2013). Which macroarthropods prefer tree stumps over soil and litter substrates. Forest Ecology and Management, 290, 30-39.

Saksa T (2013). Regeneration after stump harvesting in southern Finland. Forest Ecology and Management, 290, 79-82.

Song ZW, Tang JW (2008). Coarse woody debris mass and its nutrients stock in tropical seasonal rain forest in Xishuangbanna, Southwest China. Chinese Journal of Ecology, 27, 2033-2041. (in Chinese with English abstract) [宋泽伟, 唐建维 (2008). 西双版纳热带季节雨 林的粗死木质残体及其养分元素. 生态学杂志, 27 , 2033-2041.]

Stohlgren TJ (1988). Litter dynamics in two Sierran mixed conifer forests. II. Nutrient release in decomposing leaf litter. Canadian Journal of Forest Research, 9, 1136-1144.

Stromgren M, Egnell G, Olsson BA (2013). Carbon stocks in four forest stands in Sweden 25 years after harvesting of slash and stumps. Forest Ecology and Management, 290, 59-66.

Tan B, Wu FZ, Yang WQ, Zhang J, Xu ZF, Liu Y, Gou XL (2013). Population structure of soil arthropod in different age Pinus massoniana plantations. Chinese Journal of Applied Ecology, 24, 1118-1124. (in Chinese with English abstract) [谭波, 吴福忠, 杨万勤, 张健, 徐振锋, 刘洋, 苟小林 (2013). 不同林龄马尾松人工林土壤节肢动物 群落结构. 应用生态学报, 24, 1118-1124.]

Tang XL, Zhou GL, Zhou X, Wen DZ, Zhang QM, Yin GC 
(2003). Coarse woody debris in a monsoon evergreen broad-leaved forests of Dinghushan Nature Reserve. Acta Phytoecologica Sinica, 27, 484-489. (in Chinese with English abstract) [唐旭利, 周国逸, 周霞, 温达志, 张倩 媚, 尹光彩 (2003). 鼎湖山季风常绿阔叶林粗死木质残 体的研究. 植物生态学报, 27, 484-489.]

Tian DL, Xiang WH, Yan WD (2004). Comparison of biomass dynamic and nutrient cycling between Pinus massoniana plantation and Pinus elliottii plantation. Acta Ecologica Sinica, 24, 2207-2210. (in Chinese with English abstract) [田大伦, 项文化, 问文德 (2004). 马尾松与湿地松人 工林生物量动态及养分循环特征. 生态学报, 24, 22072210.]

Wang W, Zhang XY, Tao N, Ao D, Zeng WJ, Qian YQ, Zeng $H$ (2014). Effects of litter types, microsite and root diameters on litter decomposition in Pinus sylvestris plantations of northern China. Plant and Soil, 374, 677-688.

Wen LH, Liang HW, Wen YG, Liang JS, Huang M (2010). Preliminary study on storage of coarse woody debris in evergreen broad-leaved forests of Damingshan Mountain Nature Reserve. Guangxi Forestry Science, 39, 197-200. (in Chinese with English abstract) [温琳华, 梁宏温, 温远 光, 梁家善, 黄棉 (2010). 大明山常绿阔叶林粗死木质 残体它量的初步研究. 广西林业科学, 39, 197-200.]

Xiang WH, Tian DL (2002). Nutrient cycling in Pinus massoniana stands of different age classes. Acta Phytoecologica Sinica, 26, 89-95. (in Chinese with English abstract) [项文 化, 田大伦 (2002). 不同年龄阶段马尾松人工林养分循 环的研究. 植物生态学报, 26, 89-95.]

Xiao S, Wu FZ, Yang WQ, Chang CH, Li J, Wang B, Cao Y (2014). Understory biomass and its characteristics as affected by forest gap in the alpine forest ecosystem in West Sichuan. Ecology and Environmental Sciences, 23, 1515-1519. (in Chinese with English abstract) [肖洒, 吴 福忠, 杨万勤, 常晨晖, 李俊, 王滨, 曹艺 (2014). 川西 高山森林生态系统林下生物量及其随林窗的变化特征. 生态环境学报, 23, 1515-1519.]

Yan ER, Wang XH, Huang JJ (2005). Concept and classification of coarse woody debris in forest ecosystems. Acta Ecologica Sinica, 25, 158-167. (in Chinese with English abstract) [阎恩荣, 王希华, 黄建军 (2005). 森林粗死木 质残体的概念及其分类. 生态学报, 25, 158-167.]

Yang FF, Li YL, Liu XZ (2009). Decomposition of coarse woody debris in Schima superba of Dinghushan. Journal of Mountain Science, 4, 442-448. (in Chinese with English abstract)[杨方方, 李跃林, 刘兴诏 (2009). 鼎湖山木荷 (Schima superba) 粗死木质残体的分解研究. 山地学
报, 4, 442-448.]

Yang HX, Wang SL, Fan B, Zhang WD, Wei CE (2010). Dynamics of nutrients in an age sequence of Pinus massoniana plantation. Chinese Journal of Applied Ecology, 21, 1907-1914. (in Chinese with English abstract) [杨会侠, 汪思龙, 范冰, 张伟东, 韦翠娥 (2010). 马尾松人工林 发育过程中的养分动态. 应用生态学报，21，19071914.]

Yang LY, Dai LM, Zhang YJ (2002). Storage and decomposition of fallen wood in dark coniferous forest on the north slope of Changbai Mountain. Chinese Journal of Applied Ecology, 13, 1069-1071. (in Chinese with English abstract) [杨丽韫, 代力民, 张扬建 (2002). 长白山北坡暗 针叶林倒木咜量和分解的研究. 应用生态学报, 13, 1069-1071.]

Yang YS, Lin P, Guo JF, Lin RY, Chen GS, He ZM, Xie JS (2003). Litter production, nutrient return and leaf-litter decomposition in natural and monoculture plantation forests of Castanopsis kawakamii in subtropical China. Acta Ecologica Sinica, 23, 1278-1289. (in Chinese with English abstract) [杨玉盛, 林鹏, 郭剑芬, 林瑞余, 陈光水, 何宗明, 谢锦升 (2003). 格氏栲天然林与人工林调落物 数量, 养分归还及调落叶分解. 生态学报, 23, 12781289.]

Yuan J, Cai J, Hou L, Zhang SX (2012). Storage and decomposition of fallen wood in a Pinus tabulaeformis secondary forest at Huoditang forest region in the Qinling Mountain. Scientia Silvae Sinicae, 48(6), 141-146. (in Chinese with English abstract) [袁杰, 蔡靖, 侯琳, 张硕新 (2012). 秦 岭火地塘天然次生油松林倒木储量与分解. 林业科学, 48(6), 141-146.]

Zhang KR, Liu YD, Zhu XW, Zhang QF, Tan SD (2011). Community types and species diversity of Pinus massoniana forests of Yuelu Mountain, Changsha. Scientia Silvae Sinicae, 47(4), 86-94. (in Chinese with English abstract) [张克荣, 刘应迪, 朱晓文, 张全发, 谭淑端 (2011). 长 沙岳麓山马尾松林的群落类型划分及物种多样性分析. 林业科学, 47(4), 86-94.]

Zhang XY, Guan DS, Zhang HD (2009). Characteristics of storage and decomposition of coarse woody debris (CWD) under three forests in Guangzhou. Acta Ecologica Sinica, 10, 5227-5236. (in Chinese with English abstract) [张修 玉, 管东生, 张海东 (2009). 广州三种森林粗死木质残 体(CWD)的储量与分解特征. 生态学报, 10, 5227-5236.]

特邀编委: 代力民 责任编辑: 王 葳 


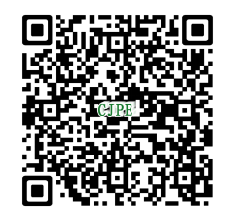

植物生态学报官网

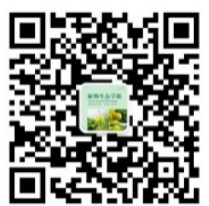

微信订阅号

期刊及学科

相关信息发布

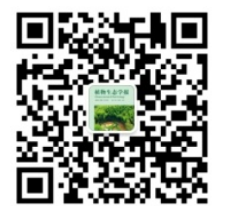

微信服务号

稿件状态查询

全文检索汶览 